\section{Dr. Excellent: The Systemic and Personal Conditions for Being an Academic Star in Communication Studies}

KOME - An International Journal of Pure Communication Inquiry

Volume 9 Issue 2, p. 65-80. (C) The Author(s) 2021

Reprints and Permission: kome@komejournal.com

Published by the Hungarian

Communication Studies Association

DOI: $\underline{\text { 10.17646/KOME.75672.64 }}$

\author{
Manuel Goyanes ${ }^{1}$ and Márton Demeter ${ }^{2}$ \\ ${ }^{1}$ Universidad Carlos III de Madrid and Democracy Research Unit, University of Salamanca, \\ SPAIN \\ ${ }^{2}$ National University of Public Service, HUNGARY
}

\begin{abstract}
Pursuing excellence is a legitimate ambition of many scholars worldwide. However, between wishful thinking and real facts lies a great leap that can only be bridged using a myriad of resources. We label these the excellence repertoire. Based on 25 interviews with successful communication scholars, we show the key role of accumulating social, economic, and institutional capital in shaping the excellence repertoire. The study argues that the fetishization of productivity might jeopardize the traditional ethos of science, in a context where research excellence may be disconnected from the quality of education.
\end{abstract}

Keywords: research excellence, field theory, communication sciences, publish or perish, productivity, academic stars

\title{
Introduction
}

One of the key factors to measure academic excellence, and which is thus crucial in tenure processes and hiring decisions is publication in top-tier journals (Tóth and Demeter, 2021; Zdenek, 2017). It is generally assumed that journals with higher impact factors are deemed more important than those with lower ones and, therefore, the quality and excellence of research publications is often derived from the scientific outlets in which they appear (Holden et al., 2006; Vanclay, 2011). In recent years, journals have become the central spaces for scientific dissemination and theoretical discussions, and publishing regularly in top journals is perceived as a sign of status, excellence, and success (Pendlebury and Adams, 2012). Moreover, since university rankings put a significant emphasis on research output (Stack, 2021), faculty members, especially at research universities that strive for better ranking positions, are under pressure to get papers published. In this context, many researchers are increasingly concerned about the degree to which their own work is considered "excellent". The secret of excellence or, as other authors in cultural studies call it, "academic stardom" (Moran, 1998; 2000) is the focus of this study.

This article explores how and why some communication scholars became so excellent. Drawing upon Bourdieu's field theory and based on 25 in-depth interviews with prominent

Address for Correspondence: Manuel Goyanes, email: mgoyanes@hum.uc3m.es

Article received on the 29th April, 2021. Article accepted on the 20th July, 2021.

Conflict of Interest: Márton Demeter is an editorial board member of KOME. 
international academics, we try to elucidate the secrets of excellence and its impact on scholars' daily-life. Our findings reveal how the social construction of excellence is mainly driven by the coordinates of its craft and psychology, arguing that both must necessarily be aligned with systemic premises. We also show the crucial role of capital accumulation in shaping the excellence repertoire, specifically in the form of social, economic and institutional resources. This study contributes to the international problematization of the publication culture in social sciences (Darbyshire, 2007; Watson, 2011), focusing on how excellence is socially constructed and achieved in practice in the communication field.

\section{Individual and Systemic Aspects Accounting for Research Excellence}

An extensive research agenda in communication studies shows that recognized excellence-as measured by holding top positions at leading universities (Burris, 2004; Cowan and Rossello, 2018; Demeter and Tóth, 2020), gatekeeping positions such as editors and editorial board members in prestigious journals (Goyanes \& de-Marcos 2020; Lauf, 2005), and publication output (Efranmanesh, Tahira and Abrizah, 2017; Moody, 2004; Tóth, 2018) - is the interplay between systemic dynamics and individual merit. Several research traditions have examined these systemic inequalities, empirically showing how they significantly favor scholars from the Western parts of the world or, more precisely, scholars educated at elite Western universities (Collyer, 2014; Enders, 2001; Fumasoli, Goastellec and Kehm, 2015). Within a world-systemic perspective, previous works have defined such research imbalances as both vertical and horizontal inequalities.

As regards horizontal inequality, research shows that the top positions of communication scholarship are mostly occupied by Western educated scholars, typically with an American background (Demeter and Tóth, 2020; Wiedemann \& Meyen, 2016). This holds not just for top positions, but also for publication output and gatekeeper positions (Goyanes \& Demeter, 2020; Enders, 2001). In terms of vertical inequality, extant research shows that, besides geopolitical differences, there are vertical differences as well, even within the center. This means that, in order to be in a leading position, it is not enough to have Western degrees, but also elite credentials such as education from Ivy League or Russell Group universities (Altbach, 2010; Clauset, Arbesman and Larremore, 2015; Cowan and Rossello, 2018; Enders, 2001). Research shows, however, that in order to acquire such an elite track record, scholars need more than individual talent and personal effort since admission to elite education is, at least in part, a consequence of social status, including family background and race (Bourdieu, 1996; Golden, 2007.

Extant research has also provided robust analytical tools to account for global geopolitical, racial, and gender inequalities in global science (Goyanes, 2020b). First, when it comes to geopolitical biases in global scholarship, imbalances are typically discussed in the terms of the Matthew effect (Bonitz, Bruckner and Scharnhorst, 1997; Merton, 1968) and deWesternization (Waisbord and Mellado, 2014; Wang, 2011). Bonitz, Bruckner and Scharnhorst (1997) directly used the Matthew-effect for the description of the inequalities between the academic representation of geopolitical locations and they argued that rich countries have disproportionally higher number of citations, grants and publication output than developing countries. They coined the term 'Matthew-effect for countries' to refer to this country level bias.

According to a number of studies, the aforementioned systemic biases hold not only for education, but also for many other aspects of career prospects (Gerhards and Carlson, 2017). This is not surprising: as career success is in many ways is determined by prior elite education, and since elite central students are more likely to have elite education than their non-core counterparts, it is most likely that, as a consequence of their elite education, they will hold a 
disproportionally greater share of power positions than their more peripheral peers (Bourdieu 1996; Clauset, Arbesman and Larremore, 2015; Demeter and Tóth 2020;).

Accordingly, elite journals that are indexed in prestigious international databases (i.e. JCR and Scopus) typically favor Western scholars that publish in Western publishing houses, write in English, and employ Western methods and practices (Istratii, 2020; Istratii and Hirmer, 2020; Narayanaswamy, 2019). These aforementioned systemic inequalities are further exacerbated by financial issues such as the higher salaries of Western scholars and the uneven distribution of international research funding between the center and the periphery (Around and Bell, 2009; Bloch and Sorensen, 2015). When discussing the excellence repertoire, we should remember these systemic dynamics that constitute a significant part of perceived excellence as it manifests itself in different aspects of a scholar's career success. Accordingly, we argue that Bourdieu's field theory might be a good starting to point from which to better understand the publication culture in the field and the role of capital accumulation, habitus and the underlying norms that regulate the field. Through 25 in-depth interviews with prominent international profiles, we try to elucidate the secrets of excellence in the international marketplace.

\section{Theoretical framework}

Bourdieu exerted heroic efforts to highlighted the role that the field of forces plays in academic life, and his later followers dedicated an enormous amount of research to this topic (Demeter, 2019; Wacquant, 2018; Wiedemann and Meyen, 2016). According to Bourdieu, in order to develop the appropriate set of winner strategies to success in a given field, i.e. what we conceptualize as the excellence repertoire, competitive agents have to acquire the winning habitus. Habitus refers to certain durable and transposable dispositions or tendencies that social agents have in order to be active during social actions (Grenfell, 2008). Bourdieu deliberately states that the most important commitment of elite universities is to make their students implement a habitus whereby elite students can demarcate themselves from students of other, less prestigious universities (Bourdieu, 1996). Accordingly, students of future academic excellence might pick up the winning habitus at elite institutions without being aware of this elitist demarcation. Moreover, elite students, even without knowing that, might develop a habitus that includes the idea that they are the "cream of the crop", and it might have implications to their future networking strategies as well. With this, they embrace the myth of meritocracy that has been extensively critized by several authors (Darbyshire, 2007; Demeter, 2020).

Bourdieu's notion of capital can be roughly conceived as the extension of the economic sense of the concept, since Bourdieu's purpose is to extend the sense of the term "capital" by employing it in a wider system of exchanges whereby various types of assets are transformed and exchanged within complex networks or circuits within and across different fields. Based on the Bourdieusian concept of capital, Demeter (2018) distinguishes four types of capital that can be related to the field of academic scholarship. The first and most important is academic capital, which can be accumulated in the form of certifications, degrees, fellowships, research grants, and work experience. Academic capital that has been collected at the top of the hierarchy (typically, in the US and other English-speaking countries) is much more valuable than that collected in more peripheral countries.

Another type of capital is social capital, which consists of demonstrable records of participation in international collaborations, research groups and associations such as, in the case of communication studies, the ICA, NCA or AEJMC. Of course, being a fellow or in a presidential position entails much more social capital than being a mere member of these associations (Wiedemann \& Meyen 2016). The third type of capital is economic capital, which is one of the main factors behind academic labor migration towards the West (Asheulova \& 
Dushina, 2014). Economic capital typically consists of factors like salary, equipment and technology for scientific activities, and the accessibility of external funds. The relatively low level of economic capital tends to inflict great damage on the career trajectory of non-Western scholars, since they frequently have to undertake other duties besides their academic work, and this "divided or parallel career paths" lifestyle often results in leaving academia.

Finally, the fourth type of capital is symbolic capital in the widest sense, which consists of many forms and aspects of contemporary recognition. Of course, this symbolic capital can easily be transferred to economic capital. For example, one of the most important manifestations of symbolic capital is the number of citations, which is a powerful asset in a job interview or an academic promotion. Other types of symbolic capital are hierarchical positions in tenure or selection committees, memberships in editorial boards of prestigious journals, and other gatekeeper positions. Lastly, the number of publications in prestigious journals should be seen as symbolic capital which, similarly to the citations scores, can be transferred to economic capital through job appointments or promotions.

Based on our aforementioned critical assessment on systemic inequalities of the field and on our recent conceptualization that applies Bourdieusian concepts to the examination of communication scholarship, this study contributes to the international problematization of publication culture in social sciences in general (Darbyshire, 2007; Watson, 2011) and in communication sciences in particular (Ang et al, 2019; Waisbord, 2019), critically exploring how measureable excellence (as it is expressed by publication records, citations, research grants and power positions) is determined by systemic pressures and biases, how it is socially constructed, and how it can be accomplished in practice.

\section{Method, Procedure and Analysis}

We conducted in-depth interviews with 25 international scholars. In order to be considered as an international scholar, our respondents should meet several criteria such as being editorial board members in international journals, publishing in international journals, and be highly cited in their research fields. While the definition of an international scholar might be blurred in a globalized field, we focus on well-known figures that have an international reputation that is expressed by international publication records, international memberships and international citations.

The semi-structured interviews were carried out between March and November 2018. We conducted semi-structured interviews, as this method allows us to reach deep knowledge from a person's "lived experience" and "perspective" (Johnson \& Rowlands, 2012, 100). From an analytical point of view, the purpose of semi-structured interviews is to find patterns from the "thick descriptions" offered by participants (Hesse-Biber \& Leavy, 2006, 119). We used purposive sampling, specifically maximum variety sampling. Following Patton (2002), participants were chosen to reflect a large diversity in information-rich cases relevant to the research interest: different universities, communication departments, and countries (see Table $1)$.

Table 1 
Sample Characteristics

\begin{tabular}{|c|c|c|c|c|c|c|c|c|c|c|}
\hline Gender & $(\%)$ & $\begin{array}{l}\text { Current } \\
\text { position }\end{array}$ & $(\%)$ & Race & $(\%)$ & $\begin{array}{l}\text { Education } \\
(\%)\end{array}$ & $\begin{array}{l}\text { BA } \\
(\%)\end{array}$ & $\begin{array}{l}\text { MA } \\
(\%)\end{array}$ & $\begin{array}{l}\mathrm{PhD} \\
(\%)\end{array}$ & $\begin{array}{l}\text { Affiliation } \\
(\%)\end{array}$ \\
\hline Male & 55 & $\begin{array}{l}\text { Associate } \\
\text { professor }\end{array}$ & 13 & White & 94 & US & 62 & 79 & 83 & 60 \\
\hline \multirow[t]{5}{*}{ Female } & 45 & $\begin{array}{l}\text { Full } \\
\text { professor }\end{array}$ & 87 & $\begin{array}{l}\text { Other } \\
\text { than } \\
\text { white }\end{array}$ & 6 & $\begin{array}{l}\text { Western } \\
\text { Europe }\end{array}$ & 17 & 12 & 12 & 20 \\
\hline & & & & & & $\begin{array}{l}\text { South } \\
\text { America }\end{array}$ & 8 & 0 & 0 & 8 \\
\hline & & & & & & Asia & 8 & 4 & 0 & 8 \\
\hline & & & & & & Canada & 0 & 0 & 0 & 8 \\
\hline & & & & & & Australia & 4 & 4 & 4 & 0 \\
\hline
\end{tabular}

As a consequence of our sampling strategy, our interviewees represented a great heterogeneity in their profiles, both in the field of expertise (political communication, media studies, journalism, advertising, health communication, etc.), the geographical level covered (multinational.), demography (men and women of different ages, races, and experiences), responsibilities (respondents included editors-in-chief of major journals, managing editors and editorial board members) and methodological approaches (quantitative and qualitative). All participants were, at the time of analysis, editorial board members of at least one major communication journal of the Journal Citation Report (Journal of Communication, Human Communication Research, Journal of Computer-Mediated Communication, New Media \& Society, Communication Research, Information, Communication \& Society etc.), and highly cited in their respective sub-disciplines.

We decided to focus on editorial boards from leading journals because we were interested in accounting for excellence according to excellent researchers. Editorial board members typically contribute to ensuring the quality of scientific journals and are selected based on their experience and prestige. Extant research has clearly demonstrated that the selection of editorial board members is usually based on the career trajectory and excellence of scholars, which generally means publishing in top journals (Burgess and Shaw 2010). Accordingly, we focus on those journals typically seen as leaders in the field: those indexed in the first quartile of the Journal Citation Report. In addition, in order to account for the different visions that may influence the social construction of excellence, our sample includes scholars that have conducted both quantitative and qualitative research. Therefore, based on our sampling strategy, the definition and secrets of excellence outlined in this study are significantly influenced by our respondents' own success in this particular marketplace of ideas.

Despite the efforts to have an inclusive sample size, the many journals (and scholars) that were left out preclude us from claiming that our findings are representative. In this regard, there are obvious limitations to our sampling strategy, as different editorial boards from other lowerranked, more critical or humanistic journals may hold a different approach towards research excellence, as expectations, priorities, and norms of research practice and/or production may diverge (Goyanes, 2020a). However, as we outlined previously, we are interested in the secrets of excellence from those scholars who combine a prominent reputation, productivity, and impact, and who hold a position at one or many editorial boards of top-ranked communication journals.

The confidentiality of interviewees was guaranteed. Given the national diversity of selected participants, the majority of interviews were conducted online via Skype. The interviews were 
transcribed by a research assistant and later codified and analyzed by the first author. To achieve saturation of ideas, we intentionally sought out both relatively young scholars (but with a strong record of publications) and highly experienced ones. The different profiles in terms of academic background, research interests, and methodological approaches enabled us to reach data saturation at 20 interviews. Data saturation is reached when there is enough information to replicate the study when the ability to obtain additional new information has been attained, and when further coding is no longer feasible. In order to re-ensure this, we included 5 more interviews, providing more robust findings.

The interview guide embraces three topic areas. The first part concerned academics' perception of their own path to excellence. Questions addressed academics' vision of their own excellence and the tactics and basic rules that they have followed to its achievement under their academic circumstances. The second part relates to their own description of the structure of excellence: questions were asked regarding what academics think about assessment exercises like RAE or RAF, the double-blind peer-review process and the role of productivity. Finally, the third part focused on academics' perceptions of the "publish or perish" system.

All interviews were recorded and transcribed verbatim following the transcription rules proposed by Dresing et al. (2015). We conducted a thematic analysis which posits "a method for identifying, analyzing and reporting patterns (themes) within data" (Braun \& Clarke 2006, 79), following the analytic six-phase procedure proposed by Braun and Clarke (2006) that allows for the systematization and transparency of the coding and analysis process. Codes and thematic maps were discussed with two independent researchers, which then informed the refinement of themes, their definition and naming. The thematic analysis allowed us to identify shared patterns across the statements of various interviewees centered around our three research interests while staying flexible to identifying other emerging themes. In the next section, we will discuss the key findings.

\section{Results}

\section{Systemic Mechanisms behind Measureable Excellence}

While only a few respondents referred to those systemic features of international academia that strongly and directly affect measureable individual excellence, their responses included considerable information regarding the implicit bias of the system. Many of our respondents emphasized the fact that excellence is a social construction, meaning that it is a relatively closed group of professionals who define who is considered excellent: "how good you are always depends on a small community", Participant 23 mentioned. Our respondents acknowledged that this small group or network consists of members of elite academic agents such as leading departments: "you know, I was at Oxford and now I'm at Stanford, and you could say that to get to these places you have to be excellent" (P5). Elite institutions are considered to serve an "institutional nepotism", as one of our respondents called it, since "people in the most successful and recognized institutions get better guidelines than other people" (P24). This assumption shows that the myth of meritocracy is typically accepted by successful scholars that tend to work at elite institutions.

Journals are also effective agents for the aforementioned institutional nepotism, since leading periodicals tend to favor authors that are close to the editorial team: "we're human beings so we like to help our friends, right? I think the journals do a pretty good job of it", Participant 13 blatantly stated. Another respondent suggested that there could be a systemic, institutional "elitist bias" that works on the editorial level, too: "I imagine that if you're an editor and you see someone from the Annenberg School or something like that, these are like 
one of the leading schools in our field. And you see a single article and you will think that if this article comes from more leading institutions it will be better." (P19). The dominance of English and Western academic standards are also considered as systemic forces that affect individual excellence. "In order to be internationally excellent, you have to abandon your native language and write in English, even if it is not your mother tongue. Consequently, you have to put in extra effort that is not needed for those scholars who have English as a first language", Participant 21 stated. Likewise, as one of our respondents summarized, internationally recognized scholars might consider writing in their original language as a mistake: "I made mistakes in my own career, at the beginning of my career I published in my mother tongue, so a lot of that kind of disappeared because nobody was citing it because people couldn't read it basically, could not understand it outside the German market. So that was kind of wasted." (P14). Besides language, there are several standards that should be followed in order to get published at the international level, and all these standards come from the Western world: "there are some formalities and standards that you should know, like for example language standards and the way how you write that stuff." (P14).

Networking and being familiar with international standards is definitely connected to systemic positions. Most respondents directly refer to the financial determination of being part of elite networks and being able to follow current norms. Excellent scholars need grants and funds in order to attend leading international conferences that are considered to be the most important forums for networking. Typically, elite Western universities have enough resources to offer travel and conference grants (Istratii, 2020), and international grants also typically go to researchers working at elite universities (Around and Bell, 2009; Bloch and Sorensen, 2015). As one of our respondents puts it, "you need to have resources. So when I started out I was in a very fortunate position and then I was able to pay my expenses to go to various conferences. So that helped, because you get to meet other people, you see what other people are doing and people get to know you." (P17). Conferences also help to get new ideas and future research agenda: "Going to conferences helps me to be more productive as I run into more opportunities at conferences than I would maybe run into if I hadn't gone to the conferences." (P6).

Finally, one of our respondents expressed the opinion that, while there might be no open nepotism on a personal level, there is a systemic bias against both racial and sexual minorities. This is a consequence of the fact that, in his opinion, editors and reviewers can guess the author's identity by the topic of the article, and thus their decision can be affected by their personal attitude. In summary, our respondents referred to two kinds of systemic determination of measureable excellence. First, there is the Western determination of language and academic standards that contribute to the development of measureable excellence. These norms can be acquired though elite education in a Western environment, which significantly favors scholars either from the Western world or from a family background that can finance an elite education. Second, the role of the infrastructure can be also interpreted in a systemic way. One should have all those resource-intensive assets (supportive and resource-abundant environment, article trackers like Scopus and Web of Science, the ability to attend conferences and access to databases and journals) that have a great impact on the path towards recognized excellence. Since these resources can be most likely obtained at elite Western universities, the system highly favors scholars working at these institutions.

\section{The Psychology and Craft of Excellence}

Most of our respondents understood academic excellence in terms of research and, more specifically, in terms of research output in "top-tier" journals. Only two participants embraced excellence as a "multidimensional construct" or a combination of "services" in three interrelated domains: "research, teaching, and service to the academic community" (P2). According 
to our participants' testimonies, the psychology of excellence is the product of different personal traits, such as passion, curiosity, enthusiasm, conscientiousness, and creativity. However, the psychology of excellence is not only a combination of "positive" emotions or individual traits, but also entails the confidence "to believe that what you are doing is good enough to be published" (P21).

In addition, most of our participants acknowledge that being "resilient" is a key ingredient for academic success because, in academia, "you get a lot of negative feedback and a lot of criticism. Academics are very good at critiques, and it's not always helpful" (P3). Beyond personal traits, there are other conditions related to the "expectations", "familiarity" and "conventions of the discipline" (P5) that have even more impact on shaping a successful career. The "adaptation" and "internalization" of all these "tacit rules", as one of our respondents stated (P9), are key to understanding the craft of research and thus to get published and excel in the field. Beyond learning the conventions of the discipline, most of our respondents believed that posing good research questions that can be empirically answered, having good training, and mastering methodologies (both qualitative and qualitative), are fundamental to getting published (and thus to excelling).

\section{The Excellence Repertoire}

The psychology and craft of excellence are key elements at an individual level to shaping greatness in scholarship. However, top scholars seldom publish by themselves and typically have significant resources at their disposal as well. We term these the excellence repertoire. Specifically, the excellence repertoire is the combination of a myriad of economic, social and institutional resources that enable outstanding scholars to design and conduct their scholarship and boost their productivity as a result (see Table 2). According to the testimonies we collected, having "good collaborators" is the most relevant asset to conducting top-quality research. However, most participants state that in order to achieve research excellence, co-authors and financial resources must be aligned. The financial resource most frequently cited is in the form of "grants", i.e. funding given by a third party to conduct empirical research and for "gathering original data, running statistics or going to international conferences", as one participant explained (P13).

Table 2

The excellence repertoire

\section{Type of Capital Specification Illustrative quotations}

Economic Grants
capital

Social capital Collaborators "Collaboration and learning from other people. I think I am more productive when I work with others in a team"

Networks "Excellence is very often a reputation, and reputation is on the way of depending on your social network with the people actually like what you do" 


\begin{tabular}{lll}
\hline $\begin{array}{l}\text { Academic/ } \\
\text { Symbolic } \\
\text { capital }\end{array}$ & $\begin{array}{l}\text { PhD Programs } \\
\text { "My PhD program shaped who I am" } \\
\text { "I think that being in an actual doctoral program } \\
\text { was fundamental to me" } \\
\text { "Having good colleagues around you is important, } \\
\text { people you can talk to, you can work with" }\end{array}$ \\
& $\begin{array}{l}\text { Students } \\
\text { "Our researchers are our students" } \\
\text { "Students have tremendous huge impact one me" }\end{array}$ \\
& $\begin{array}{l}\text { Time } \\
\text { management } \\
\text { and time to do } \\
\text { research }\end{array}$ & $\begin{array}{l}\text { resources and has a lot of teaching, you cannot } \\
\text { become a good researcher very easily" }\end{array}$ \\
& $\begin{array}{l}\text { University } \\
\text { environment }\end{array}$ & "You have to have a very supportive environment" \\
\hline
\end{tabular}

Accumulating economic and social capital seems fundamental to excellence. However, the excellence repertoire also includes key institutional resources around five key ingredients: $\mathrm{PhD}$ programs, colleagues, students, time management, and the university environment. First, for the vast majority of our respondents, the enrolment in and cultivation of a great $\mathrm{PhD}$ program is "the first step to excellence" (P23). Being trained with excellent supervisors on how to conduct empirical research and to understand the "tricks" of the research process and peer review seems fundamental. In addition, high quality training enables many $\mathrm{PhD}$ students to increase their number of publications and thus their chances to get external funding, as the following respondent acknowledges: "When I finished my doctorate, I was already used to writing papers and I was very skilled. Then it was easier to get funding." (P14).

With regards to the academic institution, our respondents believed that having "great" colleagues, grad and PhD students, and being involved in a research-intensive department were key to fostering excellence. Departmental colleagues play a fundamental role not only as potential collaborators, but also because "you can talk with them and explain your problems", as one of our respondent raised (P11). All these social interactions, immersed in a researchoriented department, create an atmosphere in which all faculty members seek to pursue academic greatness. Students were also relevant to helping our respondents grasp social reality and come up with new and original ideas. Learning new things and the motivation of some students to conduct particular research projects inspired some of our interviewees to collaborate with them and finally "get stuff published".

Finally, to be excellent, our respondents needed time, which generally meant reducing their teaching load or simply neglecting teaching duties. Finding time to write and focus on their research projects, which they typically considered as the most relevant work as academics, was fundamental to producing high-quality scholarship and being productive. These dynamics of research dominating over teaching duties might point to an important challenge that leading scholars and, most importantly, research-intensive universities are currently facing: research excellence may be disconnected from or come at the expense of quality of education.

\section{Productivity and the Publish or Perish/Flourish System}

For our respondents, productivity is key to understanding the academic dynamics of the publication culture that surrounds the scientific institution. Productivity is a "pretty fuzzy term" 
(P24), generally understood as one's record of publications. Some other participants also understood productivity "as the total number of Google Scholar citations" (P21), clearly pointing to the huge weight that citation counts have in shaping scientific success. In general terms, the concept of productivity is discussed around the possible imbalances that might be triggered in relation to the quality of scholarship and the type of scientific outlets in which that scholarly work might appear.

First, despite the assumption that being productive might be detrimental to research quality, some of our participants argue that in fact, the two are positively correlated. "I think that the sentence 'the more productive you are, the lower the quality of your work', is a lie. I think that's positive to say that the more productive you are the higher quality of your work. It is not a perfect relation. But generally speaking, I often say that you cannot have quality if you don't have quantity", a responded explained (P9). Echoing this voice, another participant stated: "You can't get more things published unless you're doing good work. So I'm sure this is a positive correlation, but it's also true that there is pressure to publish a lot and sometimes you might publish things that aren't all that great. If you had less pressure to publish, you might work more deeply on something" (P17).

However, other testimonies related productivity with quantity and not quality. Therefore, counting the number of publications, sole authorships, invitations, awards and grants becomes "the greatest indicator to know if a scholar is excellent or not" (P5). This fetishization of productivity and research credentials jeopardizes the traditional ethos of science-the advancement of human understanding, as the following participant introduces:

"I think we are moving to productivity-based on counting how many publications and citations we have, we can't leave productivity aside as the progress of the discipline. The issue of productivity metrics is important, but we should qualify it as soon as this study increases our knowledge on a topic" (P8).

The concept of productivity is also very much associated with the academic ladder and, more specifically, with the tenure-track system of most public universities in the US and the "publish or perish" institutional framework that underpins it. As one of our interviewees acknowledged, publish or perish means "to publish enough to get tenure or you're out." (P6). However, collecting research credentials mostly in form of journal publications, teaching, and service to the academic community, pushed most of our participants to the brink of intellectual collapse, pressuring them to publish as much as they can and thus generating anxiety, frustration, and even academic dropout.

Acquiring tenure means that our participants can keep their jobs almost under any circumstances, even if they stop publishing. By holding a protected job for the rest of their lives, our participants felt that they were in a position of control of their academic performance and of freedom to conduct the research they love. "The tenure system was making me have to wait to do the work I loved", one participant lamented (P6). As a result, after tenure, most of our interviewees felt relieved, and the anxiety and pressure to publish decreased dramatically. Similarly, some participants acknowledged that after tenure they radically changed their research interests, pursuing ideas that really appealed them instead of the ideas that they thought could be published or would impress the community. Therefore, on many occasions, the tenure system might jeopardize original research questions, generating desperation and even ethical research issues, as the following respondent illustrated:

"It's a really horrible system because I think it squashes good questions and I think real productivity comes when you're relaxed, as some people get their best ideas in the bathroom. So I think that it works undue pressure and I think it's painful, but it's part of an economic commercial set of research. But I think it's harmful, absolutely." (P18). 


\section{Conclusions}

The publication culture that surrounds the scientific habitus has established the norm that communication scholars must publish regularly until retirement. Publish or perish, and the subsequent anxiety and pressure that most scholars feel to meet the demands of the tenure process engender an academic field characterized by growing competition and the inflation of research credentials. In a context where being excellent is a function fundamentally derived from someone's record of publications (Butler and Spoelstra, 2012), many scholars worldwide are challenged to demonstrate their research ability and thus to show that they "are able to publish". This study contributes to international discussions on the publication culture in social sciences (Darbyshire, 2007; Watson, 2011; Demeter \& Goyanes, 2020), focusing on how excellence is socially constructed and achieved in practice in the communication field. Based on 25 interviewees with prominent scholars, our findings offer six inter-related contributions to this line of inquiry.

First, in our critical analysis, we investigated both systemic and individual conditions of the development of measureable excellence. The analysis of the interviews resulted in a complex picture of the process whereby academic excellence can be achieved in communication sciences. First, there are clear systemic determinants of international visibility and excellence that are little affected by individual factors such as talent, hard work, and intelligence. The most openly expressed systemic factors that contribute to research excellence were elite education along with a mastery of the English language and Western academic standards, all of which are connected with one's family background, nationality and the place of education. Another systemic determinant is the financial potential of one's research institution, since most preconditions of networking such as attending international conferences and being up-to-date with trending topics and methodologies need considerable financial resources. Obviously, researchers that work at elite Western universities can get financial support for networking more easily than their peripheral peers, which allows them to further reinforce their power positions.

In a Bourdieusian frame, this is a perfect example of how economic capital accumulated at Western elite institutions can be converted to social capital that can later be converted to academic capital in the form of research output, citations, and powerful positions. The recognition of the aforementioned facts led many excellent scholars to move towards elite Western norms, the English language, and elite Western institutions, all of which leads to systemic dynamics whereby academic capital is both collected and accumulated in the West. As Table 1 shows, all the analyzed researchers obtained their education in the West and they all hold Western affiliations. This systemic bias towards Western academia considerably affemight affect the individual habitus of many excellent researchers who strive to develop a professional habitus that corresponds to the norms of the field.

Second, according to our findings, excellence is generally understood as one's ability to publish in top-tier communication journals which are considered a prime form of academic capital. Our results thus confirm the general assumption that being productive and appearing in leading scientific outlets is the most important part of the habitus that leads to academic success and renown. Looking at the formalities of the field, it is rational to assume that publishing in top-tier communication journals is shorthand for excellence: having good ideas and being recognized for the quality of scholarships is generally part of the reason for being published by a leading journal. In addition, there are journals whose history makes them authoritative; accordingly, "being able" to publish there sends a message to the academic community about the quality of one's research.

At the same time, the narrow and closed definition of excellence points to the structural distortions of the field and certain research visions that delimitate excellence from "other 
things". First, taking a broad perspective on scholars' responsibilities, excellence might also be applicable not only to research but also to teaching, supervision, and service to the community (Watson, 2011). Neglecting these crucial responsibilities might also point to a zero-sum game in which quality of research might be disconnected from or come at the expense of quality of education. In a context where productivity has become a fetish for most leading academic institutions, education and administrative responsibilities might be at the greatest risk, since excellence in teaching apparently counts less when it comes to the accumulation of academic capital, thus the winner habitus concentrates much more on research than on other aspects of academic life and accordingly the habitus might become one-sided.

Third, beyond systemic features, we show how excellence is constructed and framed according to two rational coordinates: its psychology and craft. With the psychology of excellence, we refer to the personal traits and emotions (as parts of the successful and adaptive habitus) needed to conduct research deemed as excellent (passion, motivation, creativity, etc.). Our results demonstrate that, beyond the psychology of excellence, the craft aspect involves 1) understanding the norms, values, and conventions that shape the form and contents of the field of forces; and 2) translating this information into a successful habitus by (not necessarily consciously) following the standards and scientific procedures generally established in science. In short, it requires following the research conventions, interests and values of a research community and conducting "sound research" based on tacit rules of the scientific craft, which were acquired at elite universities. Research professionalism is, therefore, a function of two aspects: the norms and values of a given sub-discipline and the practical implementation of those conventions, i.e. in a research paper.

Fourth, this study addresses the myriad resources needed to boost one's capital accumulation and thus to excel or to challenge the norms of what excellence is. Our results indicate that the accumulation of capital is crucial for shaping a highly successful academic career, specifically: economic capital, social capital, symbolic capital, and academic capital. We label this accumulation the excellence repertoire and show how it manifests in practical terms. In particular, the excellence repertoire includes the accumulation of research grants and collaborators, the design and care of scientific networks, the development of research-intensive $\mathrm{PhD}$ programs, the control of interactions with key doctoral and graduate students, time management in order to focus on research, and the stabilization of academic institutions inspired by the motto "research first". In general terms, the excellence repertoire is the accumulation and management of resources at the disposal of excellent researchers, understood as those scholars that clearly surpass the basic criteria imposed by scientific bureaucracies and research communities in promotion processes. Scholars under this umbrella of resources are able to propose as many research questions as their repertoire allows them to, and develop a great capacity to empirically answer the former, mobilizing different kinds of capital accumulated during their scientific careers.

Fifth, our results show how research productivity is increasingly equated not only with quality but also with quantity. These opposing discourses are framed according to disputes around normative discussions about the objectives and ethos of communication research. Institutionally supported by the tenure-track system, the fetishization of productivity and research credentials are crucial to understanding the psychological costs not only for excelling, but for being in the academic system as a complex field. Despite the fact that obtaining tenure means a permanent, protected job for life, it also creates dysfunctionalities and distortions in top scholars: many have to wait until their promotion to work on the projects they love. The tenure-track system thus represents an academic process in which scholars have to test their research skills and prove they can contribute in order to advance their discipline further. At the same time, it may also create frustration and desperation as the tenure clock ticks, calling into question aspirants' identities and potentially causing them to neglect challenging ideas. 
Sixth, our findings might also help provide guidance to scholars in developing their academic careers. On the one hand, our evidence shows that there are considerable systemic forces that play crucial roles in determining career development and measurable excellence. Scholars that either originated from or were educated in the center are favored over their noncore competitors, and this feature of the system should be taken into consideration. Peripheral scholars should invest extra efforts in acquiring those norms and habits that are natural for their central peers. According to our respondents, while the standardization and the mandatory nature of Western norms are sometimes contested, adapting to them still seems inevitable for international recognition. In order to acquire familiarity with Western norms and current trends in both methodology and topics, scholars should both follow trending literature and attend international conferences, since being up-to-date and building networks were considered as very important parts of success. Most of our respondents also referred to the importance of teamwork, so aspiring scholars should continuously monitor the international field in order to connect with researchers working on similar topics.

Selecting the appropriate journal in which to publish was also said to be very important, thus emerging scholars should be familiar with the topics, accepted methodologies, and audience of the leading journals in the field. On the other hand, the systemic bias in the field should be also criticized, and leading scholars in power positions such as journal editors and tenure committees might want to take into account those implicit biases that were mentioned by our respondents. Having elite degrees from prestigious universities, mastery of the English language, and trending methods are not always the result of individual excellence, but of systemic forces as well. Consequently, if powerful agents of the field are committed to the equality and equity of communication scholarship, they might consider systemic biases and try to balance their assessment of measureable excellence by weighting with the systemic features of the field such as education, language proficiency, and participation in elite academic networks.

\section{Limitations and Future Research Directions}

This study has some limitations that should be addressed in subsequent studies. First, as a consequence of our more general perspective, we did not include some potentially significant influencers of career success such as gender and race, nor did we formulate specific questions related to these features in our interviews. Second, and perhaps more important, our sample was not representative in terms of these specific demographic features, and we had only two non-white participants. Thus, on the basis of our sample, it would not be possible to draw conclusions regarding racial or gender inequities in the field. These limitations of the study should be addressed by future research that directly aims to investigate the possible role of gender and race in the development of research excellence and career paths.

Third, future studies may consider empirically problematizing how scholars change their research agenda after receiving tenure or a promotion to full professor. As far as this research is concerned, we only superficially touched on the impact of the tenure system on academic performance and scholars' research interests. Therefore, future studies may consider empirically examining scholars' research paths before and after getting tenure, relying also on scientometric data (i.e. publication records and citations). Fourth and finally, future studies may also account for how an activist approach to research production may trigger divergent approaches to research excellence and to scholars' feeling of belonging/marginalization in the field. In our interview guide, we did not include questions on these issues, because we aimed to specifically problematize excellence from "hegemonic" or "standard" research paths. These limitations aside, our study critically contributes to the current discussion on how excellence is socially constructed and how it can be achieved in practice in communication science. 


\section{References}

Altbach, P. G. (2010). Preface. In G. Goastellec (Ed.), Understanding inequalities in, through and by higher education. Rotterdam: Sense Publishers.

Asheulova, N. \& Dushina, S. (2014). Research career development in Russia: the role of international mobility In Weijden, I. \& N. Asheulova, N. (2014). (Re)searching scientific careers. St Petersburg: Nestor-Historia, 171-196.

Bonitz, M., Bruckner, E., \& Scharnhorst, A. (1997). Characteristics and impact of the Matthew effect for countries. Scientometrics, 40(3), 407-422. CrossRef

Bourdieu, P. (1988). Homo academicus. Stanford: Stanford University Press.

Bourdieu, P. (1996). The state nobility. Elite schools in the field of power. Oxford, UK: Polity Press.

Bourdieu, P. (2004). Science of science and reflexivity. Cambridge: Polity Press.

Braun, V. \& Clarke, V. (2006). Using thematic analysis in psychology. Qualitative Research in Psychology, 3(2), 77-101 CrossRef

Burgess, T. F., \& Shaw, N. E. (2010). Editorial board membership of management and business journals: A social network analysis study of the Financial Times 40. British Journal of Management, 21(3), 627-648. CrossRef

Burris, V. (2004). The academic caste system: Prestige hierarchies in Ph.D. exchange networks. American Sociological Review, 69(2), 239-264. CrossRef

Butler, N., \& Spoelstra, S. (2012). Your excellency. Organization, 19(6), 891-903. CrossRef

Clauset, A., Arbesman, S., \& Larremore, D. B. (2015). Systematic inequality and hierarchy in faculty hiring networks. Science Advances, 1(1), 1-6. CrossRef

Collyer, F. (2014). Sociology, sociologists, and core-periphery reflections. Journal of Sociology, 50(3), 252-268. CrossRef

Cowan, R., \& Rossello, G. (2018). Emergent structures in faculty hiring networks, and the effects of mobility on academic performance. Scientometrics, 117, 527-562. CrossRef

Darbyshire, P. (2007). 'Never mind the quality, feel the width': The nonsense of 'quality', 'excellence', and 'audit' in education, health and research. Collegian, 15(1), 35-41. CrossRef

Demeter, M. (2018). Theorizing international inequalities in communication and media studies. A field theory approach. KOME: An International Journal of Pure Communication Inquiry 6(2), 92-110. CrossRef

Demeter, M. (2019). The world-systemic dynamics of knowledge production: The distribution of transnational academic capital in social sciences. Journal of World-Systems Research (25)1, 112-144. CrossRef

Demeter, M. (2020). Academic Knowledge Production and the Global North. Questioning Inequality and Underrepresentation. London: Palgrave Macmillan.

Demeter, M. \& Tóth, T. (2020). The world-systemic network of global elite sociology: the western male monoculture at faculties of the top one-hundred sociology departments of the world. Scientometrics, 124, 2469-2495. CrossRef

Demeter, M., \& Goyanes, M. (2020). A world-systemic analysis of knowledge production in international communication and media studies: the epistemic hierarchy of research approaches. The Journal of International Communication, 27(1), 38-58. CrossRef

Dresing, T., Pehl, T. \& Schmieder, C. (2015). Manual (on) transcription. Transcription conventions, software guides and practical hints for qualitative researchers. 3rd English Edition. retrieved from http://www.audiotranskription.de/english/transcriptionpracticalguide.htm 
Efranmanesh, M., Tahira, M., \& Abrizah, A. (2017). The publication success of 102 nations in Scopus and the performance of their Scopus-indexed journals. Publishing Research Quarterly, 33(4), 421-433. CrossRef

Enders, J. (2001). A chair system in transition: Appointments, promotions, and gate-keeping in German higher education. Higher Education, 41(1/2), 3-25. CrossRef

Fumasoli, T., Goastellec, G., \& Kehm, B. M. (2015). Academic work and careers in Europe: Trends, challenges, perspectives. New York: Springer.

Gerhards, J., Hans, S., \& Carlson, S. (2017). Social class and transnational human capital. How middle and upper-class parents prepare their children for globalization. London: Routledge.

Grenfell, M. (2008). Pierre Bourdieu. Key concepts. Stocksfield: Acumen Publishing.

Goyanes, M. (2020a). Editorial boards in communication sciences journals: Plurality or standardization? International Communication Gazette, 82(4), 342-364. CrossRef

Goyanes, M. (2020b). Meta-investigación en comunicación: antecedentes, efectos y retos de una investigación y gobernanza estandarizada. Profesional de la Información, 29(4). CrossRef

Goyanes, M. \& de-Marcos, L. (2020). Academic Influence and Invisible Colleges through Editorial Board Interlocking in Communication Sciences: A Social Network Analysis of Leading Journals. Scientometrics, 123, 791-811. CrossRef

Goyanes, M. \& Demeter, M. (2020). How the Geographic Diversity of Editorial Boards Affects What Is Published in JCR-Ranked Communication Journals. Journalism and Mass Communication Quarterly, 97(4), 1123-1148. CrossRef

Hesse-Biber, S. N. \& Leavy, P. (2006). The practice of qualitative research. London: SAGE.

Holden, G., Rosenberg, G., Barker, K. \& Onghena, P. (2006). An assessment of the predictive validity of impact factor scores: Implications for academic employment decisions in social work. Social Work Practice, 16(6), 613-624. CrossRef

Johnson, J. M. \& Rowlands, T. (2012). The Interpersonal dynamics of in-depth interviewing. The SAGE handbook of interview research: The complexity of the craft, edited by Gubrium, J. F., Holstein, J. A., Marvasti, A. B., and McKinney, K. D., 99-114. Thousand Oaks: SAGE.

Lauf, E. (2005). National diversity of major international journals in the field of communication. Journal of Communication, 55(1), 129-151. CrossRef

Merton, R. K. (1968). The Matthew effect in science. The reward and communication systems of science are considered. Science, 159, 56-63.

Moody, J. (2004). The structure of a social science collaboration network: Disciplinary cohesion from 1963 to 1999. American Sociological Review, 69(2), 213-238. CrossRef

Moran, J. (1998). Cultural studies and academic stardom. International Journal of Cultural Studies, 1(1), 67-82.

Moran, J. (2000). Star authors: literary celebrity in America. London: Pluto Press.

Patton, M. Q. (2002). Qualitative research \& evaluation methods. Thousand Oaks: SAGE.

Pendlebury, D. \& Adams, J. (2012). Comments on a critique of the Thomson Reuters journal impact factor. Scientometrics, 92(2), 395-401. CrossRef

Stack, M. (2021). Global University Rankings and the Politics of Knowledge. University of Toronto Press.

Tóth, J. (2018). US journals can afford to remain regional, but we can not. Author distributionbased internationality of Eastern European Communication Journals. KOME: An International Journal of Pure Communication Inquiry, 6(2), 1-15. CrossRef

Tóth, J., \& Demeter, M. (2021). Prestige and independence-controlled publication performance of researchers at 14 Hungarian research institutions between 2014 and 2018: A data 
paper. KOME: An International Journal of Pure Communication Inquiry, 9(1), 41-63. CrossRef

Wacquant, L. (2018). Bourdieu comes to town: Pertinence, principles, applications. International Journal of Urban and Regional Research, 42(1), 90-105. CrossRef

Waisbord, S. (2019). Communication: A post-discipline. London: Polity Press.

Waisbord, S. \& Mellado, C. (2014). De-westernizing communication studies: A reassessment. Communication Theory, 24, 361-372. CrossRef

Wang, G. (2011). De-westernizing communication research. Altering questions and changing frameworks. London: Routledge.

Watson, C. (2011). Accountability, transparency, redundancy: academic identities in an era of 'excellence'. British Educational Research Journal, 37(6), 955-971. CrossRef

Wiedemann, T. \& Meyen, M. (2016). Internationalization through Americanization: The expansion of the International Communication Association's leadership to the world. International Journal of Communication, 10, 1489-1509.

Zdenek, R. (2018). Editorial board self-publishing rates in Czech economic journals. Science and Engineering Ethics, 24(2), 669-682. CrossRef 